Vol. 2, No.1, Januari - Juni 2017

ISSN : 2502-4736

Fakultas Pertanian UNIVERSITAS TRIDINANTI

PALEMBANG

$\frac{3}{3}$

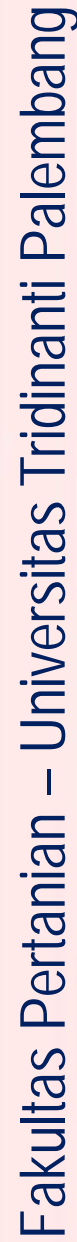

G)
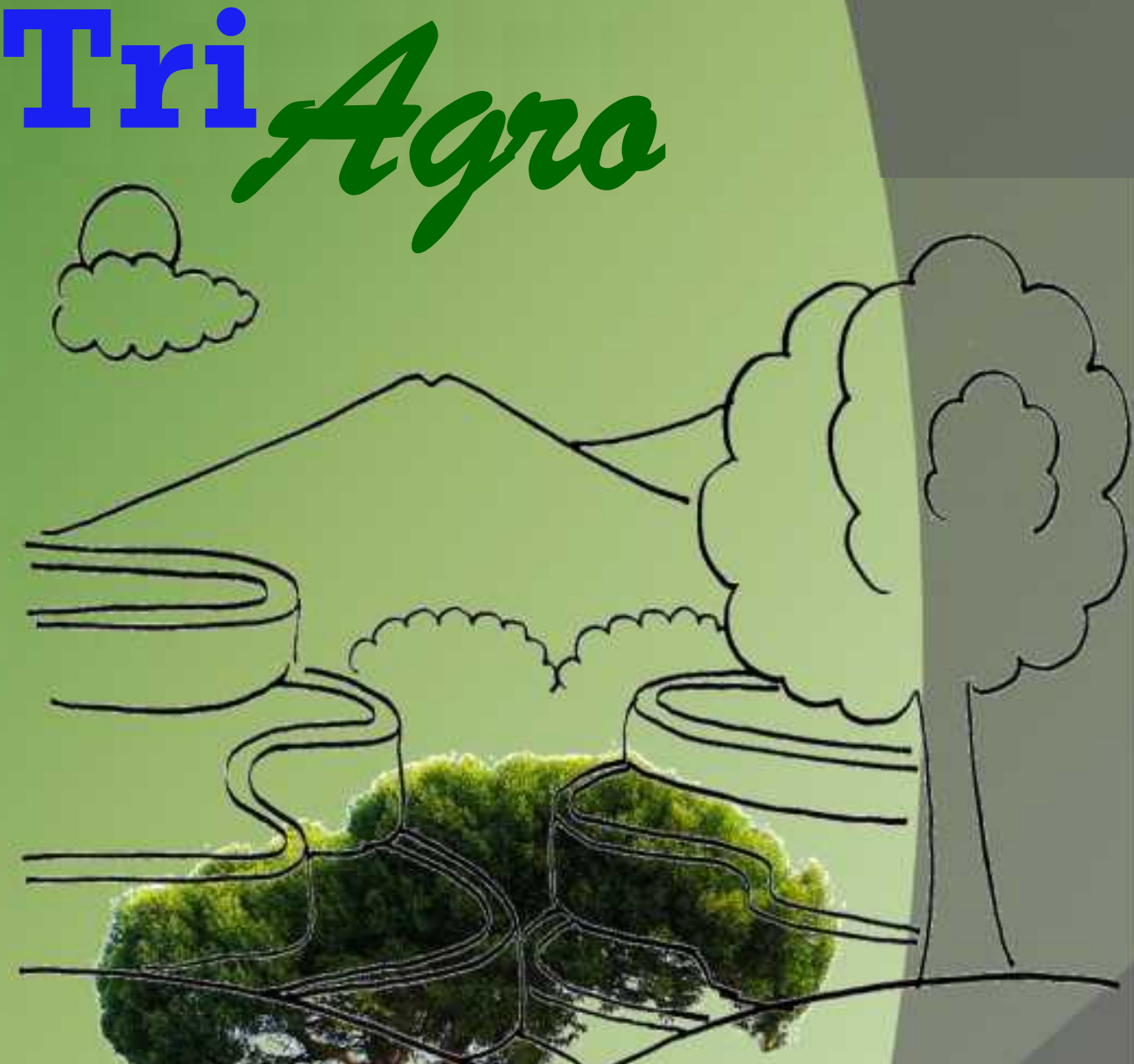

JURNAL Trišrgea

Alamat Redaksi : Fakultas Pertanian Universitas Tridinanti Jalan Kapten Marzuki No, 2446 Kamboja Palembang 30129 Telp. 0711-378387 


\section{Jurnal TRIAGRO}

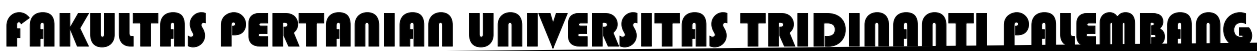

\section{Dewan Redaksi}

Pelindung

Pembina

Pimpinan Umum

Ketua Penyunting

Penyunting Pelaksana

Penyunting Ahli

Dewan Redaksi

Distribusi \& Website
: Dr. Ir. Hj. Manisah MP (Rektor)

: Dr. Nasir Sp. M.Si

: Miranty Trinawaty SP. M.Si

: Prof. Dr. Edizal M.S

- Prof. Dr. Edizal M.S

- Dr.Ir Faridatul Mukminah M.Sc

- Dr. Ir Ruarita RK. MP

: 1. Dr. Ir. Nurmayulis, MP (Universitas Sultan Ageng

Tirtayasa)

2. Dr. Munajat, SP. M.Si (Universitas Baturaja)

:

- Ir. Setiawaty MP

- Ir. Meryanto, M.Si

- Ir. Rostian Nafery, M.Si

- Ir. Ursula Damayanti, MP

- Ir. Ekanovi Aktiva, MM

- Ir. Hj. Yuliantina Azka, MP

: Nova Tri Buyana, Sp 


\section{DAFTAR ISI}

1 RESPON EKSPLAN TANAMAN KENTANG (Solanum tuberrosum L.)

VARIETAS GRANOLA TERHADAP DOSIS PUPUK DAUN DAN KONSENTRASI AIR KELAPA

Rostian Nafery, Zulkarnain Husny, Wendri Pranata *).

2 RESPON PERTUMBUHAN DAN HASIL TANAMAN JAGUNG MANIS

6

(Zea mays saccharata Sturt.) AKIBAT PEMBERIAN BERBAGAI DOSIS

PUPUK ORGANIK CAIR

Ruarita R.K, Ridwan Hanan, Achmad W.A

3 PENGARUH PEMBERIAN ZAT PENGATUR TUMBUH (ZPT)

TERHADAP PERTUMBUHAN DAN HASIL TANAMAN JAGUNG

MANIS (ZEA MAYS SACCHARATA STURT.)

Yuliantina Azka, Meriyanto, Yogi Romadi

PENGARUH PEMBERIAN LIMBAH LUMPUR KERING KELAPA

4 SAWIT TERHADAP PERTUMBUHAN DAN PRODUKSI TANAMAN

TOMAT (Solanum lycopersicum L.)

Bastani Sepindjung, Faridatul Mukminah, Henry Ardiansyah

PENGARUH PEMBERIAN BERBAGAI KONSENTRASI LARUTAN

NUTRISI HIDROPONIK TERHADAP PERTUMBUHAN DAN HASIL

TANAMAN SELADA MERAH (Lactuca sativa L.)DENGAN SISTEM Deep

Flow Technique (DFT)

Meriyanto, Busroni Asnawi, Sari Apriyani

6 PENGARUH PEMBERIAN LARUTAN NUTRISI HIDROPONIK

DENGAN BERBAGAI KONSENTRASI TERHADAP PERTUMBUHAN

DAN HASIL TANAMAN SELADA MERAH (Lactuca sativa L.) DENGAN SISTEM DEEP FLOW TECHNIQUE (DFT)

Meriyanto, Bastani Sepindjung, Rinti Mandasari. 


\section{Pedoman Penulisan Artikel Ilmiah \\ Jurnal TRIAgro \\ Fakultas Pertanian Universitas Tridinanti Palembang}

1. Jurnal ini direncanakan terbit tiga kali dalam setahun, terbuka untuk umum yang ingin mempublikasikan hasil karyanya. Artikel yang ditulis meliputi hasil penelitian di bidang sains.

2. Semua naskah makalah disertai pernyataan bahwa naskah tersebut belum pernah diterbitkan sebelumnya oleh penerbit lain.

3. Setiap naskah yang diterima akan ditinjau/ditelaah oleh ahli dibidangnya sebelum diterbitkan.

4. Naskah tidak dapat diterima jika mengandung unsur politik, komersialisme dan subyektifitas yang berlebihan.

5. Simbol dan terminologi yang digunakan adalah simbol dan terminologi yang lazim digunakan di bidang keahlian masin-masing.

6. Penulis menyetujui untuk mengalihkan hak ciptanya ke redaksi, jika naskahnya diterima untuk diterbitkan.

7. Artikel ditulis dalam bahasa Indonesia atau Inggris. Minimal 10 halaman dan maksimal 15 halaman, termasuk daftar pustaka dan lampiran : ukuran kertas A4, spasi 1,5, margin kiri $4 \mathrm{~cm}$, margin kanan, atas dan bawah masing-masing $3 \mathrm{~cm}$, menggunakan Times New Roman Font 11.

8. Artikel diketik dengan program MS Word, penulis dimohon mengirimkan satu print out dan satu CD yang berisi artikel, cantumkan alamat email dan no telepon/hp penulis untuk keperluan konfirmasi tentang tulisan yang dikirimkan ke redaksi.

9. Artikel dilengkapi :

Abstrak tidak lebih dari 200 kata dengan kata-kata kunci, biodata singkat penulis dan identitas penelitian dicantumkan sebagai cat kaki pada halaman pertma artikel.

10. Penulisan daftar pustaka mengikuti penulisan yang baik dan benar 


\section{KATA PENGANTAR}

Terima kasih atas berkah Tuhan Yang Maha Kuasa dan Rahmat-Nya, maka Jurnal TriAgro Fakultas Pertanian Universitas Tridinanti Palembang ini dapat diterbitkan. Jurnal ini diharapkan dapat menampung informasi dunia pertanian modern dan menyebarkan informasi di lingkup pertanian baik secara umum maupun khusus, penerbitan jurnal ini diharapkan dapat menjadi sarana untuk menampung tulisan-tulisan ilmiah pertanian.

Dewan redaksi mengucapkan terima kasih kepada semua pihak yang telah memerikan bantuan teknis maupun non teknis untuk terbitnya jurnal TriAgro ini. Dewan redaksi sangat mengharapkan partisipasi peneliti untuk menyumbangkan tulisannya ke jurnal TriArgro ini guna menjaga kelancaran penerbitan, yaitu dua kali setahun.

Dewan redaksi mengucapkan terima kasih kepada Bapak/Ibu/Saudara yang telah berpartisipasi pada jurnal edisi ini. Semoga Jurnal ini dapat memberikan manfaat kepada Bapak/Ibu/Saudara semuanya. 


\title{
PENGARUH PEMBERIAN LIMBAH LUMPUR KERING KELAPA SAWIT TERHADAP PERTUMBUHAN DAN PRODUKSI TANAMAN TOMAT (Solanum lycopersicum L.)
}

\section{THE EFFECT OF DRIED SEWAGE SLIDGE OIL PALM ON GROWTH AND YIELD OF TOMATO PLANTS (SOLANUM LYCOPERSICUM L.)}

\author{
${ }^{1}$ BASTANI SEPINDJUNG, ${ }^{2}$ FARIDATUL MUKMINAH, ${ }^{3}$ HENRY ARDIANSYAH \\ ${ }^{12}$ Dosen Program Studi Agroteknologi, ${ }^{3}$ Mahasiswa Program Studi Agroteknologi \\ Program Studi Agroteknologi Fakultas Pertanian Universitas Tridinanti Palembang \\ Jl. Kapten Marzuki No. 2446 Kamboja Palembang 30129
}

\begin{abstract}
Bastani Sepindjung, Faridatul Mukminah dan Henry Ardiansyah. The effect of solid waste (sludge) of oil palm on growth and yield of tomato plants (Solanum lycopersicum L.). The aims of this study was to investigate the effect of solid waste (sludge) of oil palm on growth ann yield of tomato plants. This research was conducted on October 2015 until February 2016 at the village of Sumber Baru, Mesuji Raya, Ogan Komering Ilir, South Sematera Provice. The experiment design was completely randomized design (CRD) with 5 (five) treatments and 5(five) replications. The treatments were : $0 \%$ of sludge (F1), $20 \%$ of sludge (F2), $40 \%$ of sludge (F3),60\% of sludge (F4), 80\% of sludge (F5). Observatioms began when plants were transplanted into polybags. The parameters measured were plant height $(\mathrm{cm})$, flowering date (day after planting), weight of fruits (gram), number of fruits, and avarege of fruits weight (gram). The treatment of $80 \%$ of sludge (F5) affected signifantly on flowering date, weight of fruits and number of fruits.
\end{abstract}

Keyword : Oil palm, sludge (solid waste)

\section{RINGKASAN}

BASTANI SEPINDJUNG, FARIDATUL MUKMINAH DAN HENRY ARDIANSYAH. Penelitian ini bertujuan untuk mengetahui pengaruh pemberian limbah lumpur kering kelapa sawit terhadap pertumbuhan dan produksi tanaman tomat (Solanum lycopersicum L.). Penelitian dilakukan pada bulan Oktober 2015 sampai dengan bulan Februari 2016 di desa Sumber Baru,Kecamatan Mesuji Raya,Kabupaten Ogan Komering Ilir, Provinsi Sumatera Selatan. Rancangan penelitian ini menggunakan rancangan acak kelompok (RAK), Perlakuan adalah persentase lumpur kering dengan tanah dimana terdapat lima perlakuan sebagai berikut ; $\mathrm{F} 1=0 \%$, $\mathrm{F} 2=20 \%, \mathrm{~F} 3=40 \%, \mathrm{~F} 4=60 \%$ dan $\mathrm{F} 5=80 \%$. Setiap perlakuan diulang sebanyak lima kali dengan menggunakan tiga tanaman sampel. Pengamatan dimulai sejak dipindahkan ke dalam polybag. Perubahan yang diamati dalam penelitian ini yaitu tinggi tanaman $(\mathrm{cm})$, umur berbunga(hari), berat buah (gram),jumlah buah (butir), dan berat rata-rata buah (gram). Berdasarkan hasil penelitian yang telah dilaksanakan, diperoleh kesimpulan bahwa pemberian limbah lumpur kering kelapa sawit berpengaruh nyata terhadap tinggi tanaman,umur berbunga,berat buah, dan jumlah buah tanaman tomat yaitu pada perlakuan F5. 
Kata kunci : kelapa sawit, limbah lumpur kering.

\section{PENDAHULUAN}

penting bagi usaha pertanian karena kehidupan dan perkembangan tumbuhtumbuhan dan segala makhluk hidup di dunia sangat memerlukan tanah. Akan tetapi arti yang penting ini kadang-kadang diabaikan oleh manusia. Tanah menjadi gersang dandapat menimbulkan bencana, tidak lagi menjadi sumber bagi kehidupan (Mulyani, 2010).

Menurut Isamawati (2003), pengembalian bahan organic ke dalam tanah adalah hal mutlak dilakukan untuk mempertahankan lahan pertanian agar tetap produktif. Dua alasan yang sering dikemukakan para ahli, yang pertama adalah pengolahan tanah yang dangkal selama bertahun-tahun mengakibatkan menurunya kandungan $\mathrm{C}$ dan $\mathrm{N}$-organik, kedua adalah penggunaan pupuk kimia seperti Urea, KCL, dan TSP yang melampaui batas efisiensi teknis dan ekonomis sehingga efisiensi dan pendapatan bersih yang diterima petani dari setiap unit pupuk yang digunakan semakin menurun, kedua alasan tersebut memberikan dampak buruk bagi pertanian di masa mendatang jika tidak dimulai tindakan antisipasinya. Sejalan dengan berkembangnya isi back to nature untuk memenuhi produk pertanian organic dengan berbagai persyaratan yang semakin meningkat, banyak orang berupaya mengembangkan teknologi memanfaatkan bahan-bahan organic untuk digunakan sebagai pupuk, melalui berbagai penelitian diperoleh kesimpulan bahwa tanpa bahan organic system pertanian akan bersifat rapuh (Bergeret, 1987)

Abdoellah (2002), melaporkan bahwa dengan bertambahnya kekuatiran akan adanya pengaruh buruk terhadap kesehatan akibat pencemaran pupuk kimia, kini mulai ditingkatkan kembali penggunaan bahan organic serta mengurangi penggunaan pupuk buatan (anorganik). Disamping berfungsi untuk memperbaiki sifat fisika tanah, bahan organik juga sangat membantu menyediakan unsur hara yang diperlukan tanaman.

Salah satu tindakan yang dapat dilakukan adalah memanfaatkan limbah kelapaa sawit sebagai penambah unsur hara dalam tanah. Kelapa sawit adalah salah satu komoditi andalan Indonesia yang perkembanganya sangat pesat. Selain produksi minyak kelapa sawit yang tinggi, produk samping atau limbahnnya juga tinggi. Secara umum limbah dari pabrik kelapa sawit. Lokasi penelitian bertempat di Desa Sumber Baru,Kecamatan Mesuji Raya,Kabupaten Ogan Komering Ilir pada bulan Oktober 2015 sampai dengan bulan Februari 2016.

\section{BAHAN DAN ALAT}

Bahan yang digunakan dalam penelitian ini adalah benih tomat (Solanum lycopersicum $L$.) varietas mutiara atau nama versi tidak resminya adalah tomat ceri dan media tanam limbah lumpur kering kelapa sawit.

Alat yang digunakanan dalam penelitian ini adalah alat tulis, mistar, timbangan, kamera, cangkul, sabit atau parang, pisau, polybag, ember, sprayer, dan plastik.

\section{METODE PENELITIAN}

Penelitian ini menggunakan metode eksperimen dengan menggunakan rancangan acak kelompok (RAK) yang terdiri dari lima perlakuan dan lima ulangan. Setiap perlakuan terdiri dari 10 tanaman dengan 3 tanaman sampel dan dibutuhkan 250 tanaman dalam polybag. Parameter yang 
akan diamati dalam penelitian ini meliputi beberapa factor yaitu sebagai berikut: a. Tinggi tanaman $(\mathrm{cm})$. b. Umur tanaman tomat berbunga (hari). c. Jumlah buah per tanaman tomat(butir). d. Berat buah per tanaman tomat (gram). e. Berat rata-rata buah (gram).

Perlakuan yang diuji dalam penelitian ini adalah dengan persentase campuran limbah lumpur kering sawit sebagiai berikut): $\mathrm{F} 1=0 \%$ (tanpa limbah lumpur kering kelapa sawit atau 100\% tanah), F2=20\% (limbah lumpurkering kelapa sawit), $\mathrm{F} 3=40 \%$ (limbah lumpur kering kelapa sawit), F4=60\% (limbah lumpur kering kelapa sawit, F5=80\%(limbah lumpur kering kelapa sawit).

\section{HASIL DAN PEMBAHASAN}

Hasil pengamatan rerata analisis keragaman terhadap semua parameter.

Tabel 1. Hasil analisis keragaman terhadap semua peubah yang diamati.

\begin{tabular}{|c|c|c|}
\hline Parameter Pengamatan & F-hitung & KK (\%) \\
\hline \multicolumn{3}{|l|}{ Tinggi tanaman $(\mathrm{cm})$} \\
\hline Minggu ke-1 & $0.03^{\mathrm{tn}}$ & 16.29 \\
\hline Minggu ke-2 & $5.09^{\mathrm{sn}}$ & 9.09 \\
\hline Minggu ke-3 & $7.09^{\mathrm{sn}}$ & 10.73 \\
\hline Minggu ke-4 & $8.79^{\mathrm{sn}}$ & 8.59 \\
\hline Minggu ke-5 & $14.18^{\mathrm{sn}}$ & 5.60 \\
\hline Umur berbunga (hari) & $5.17^{\mathrm{sn}}$ & 2.77 \\
\hline \multicolumn{3}{|l|}{ Jumlah buah (butir) } \\
\hline Panen ke-1 & $12.26^{\mathrm{sn}}$ & 14.96 \\
\hline Panen ke-2 & $28.50^{\mathrm{sn}}$ & 11.54 \\
\hline Panen ke-3 & $8.80^{\mathrm{sn}}$ & 23.41 \\
\hline Panen ke-4 & $43.41^{\mathrm{sn}}$ & 9.87 \\
\hline Panen ke-5 & $22.56^{\mathrm{sn}}$ & 12.14 \\
\hline Panen ke-6 & 92.28 & 5.49 \\
\hline \multicolumn{3}{|l|}{ Berat buah (g) } \\
\hline Panen ke-1 & $6.32^{\mathrm{sn}}$ & 21.82 \\
\hline Panen ke-2 & $21.05^{\mathrm{sn}}$ & 14.64 \\
\hline Panen ke-3 & $21.64^{\mathrm{sn}}$ & 12.93 \\
\hline Panen ke-4 & $23.99^{\mathrm{sn}}$ & 12.81 \\
\hline Panen ke-5 & $13.76^{\mathrm{sn}}$ & 15.23 \\
\hline Panen ke-6 & $27.84^{\mathrm{sn}}$ & 9.12 \\
\hline Berat rata-rata buah $(\mathrm{g})$ & $0.48^{\mathrm{sn}}$ & 6.37 \\
\hline \multirow{2}{*}{ F Tabel } & 0.05 & 3,01 \\
\hline & 0,01 & 4.77 \\
\hline \multicolumn{3}{|l|}{ Keterangan : } \\
\hline sn $\quad=$ Berpengaruh $\mathrm{s}$ & & \\
\hline$=$ Berpengaruh $\mathrm{t}$ & & \\
\hline $\mathrm{n} \quad=$ Berpengaruh $\mathrm{n}$ & & \\
\hline KK $=$ Koefisien Ker & & \\
\hline
\end{tabular}




\section{Tinggi Tanaman $(\mathrm{cm})$}

Hasil analisis keragaman pada tabel 1 menunjukan bahwa perlakuan pupuk organik limbah lumpur kering kelapa sawit berpengaruh tidak nyata pada minggu ke 1 :

Tabel 2. Pengaruh pemberian limbah lumpur kering kelapa sawit terhadap tinggi tanaman $(\mathrm{cm})$ pada minggu ke 1,2,3,4,dan 5 .

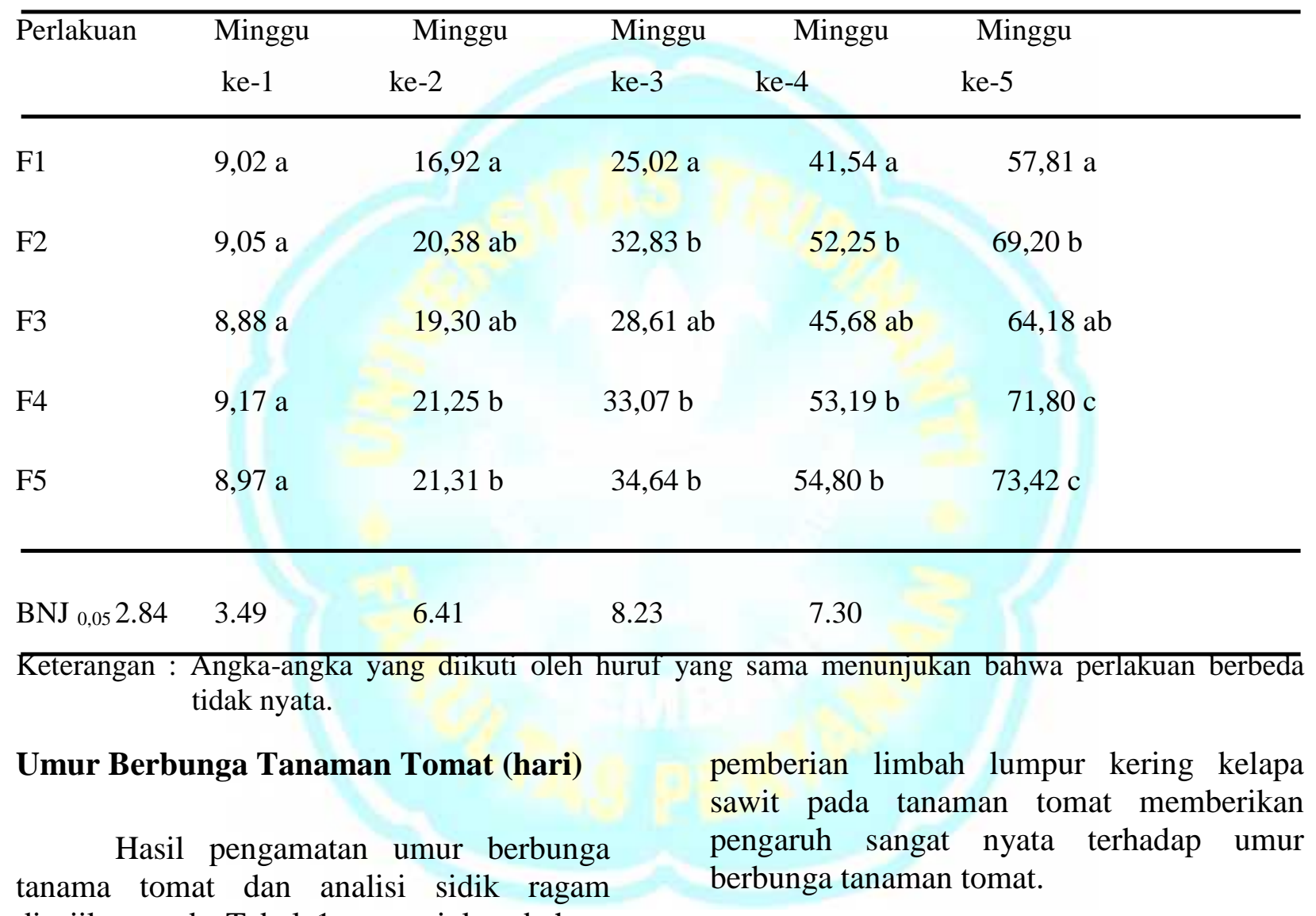

disajikan pada Tabel 1 menunjukan bahwa

Beda masing-masing perlakuan berdasarkan uji BNJ disajikan tabel 3 di bawah ini :

Tabel 3. Pengaruh pemberian limbah lumpur kering kelapa sawit terhadap umur berbunga tomat.

\begin{tabular}{ll}
\hline Perlakuan & Rerata \\
F5 & $51.20 \mathrm{a}$ \\
\hline F4 & $51.40 \mathrm{a}$ \\
F3 & $52.00 \mathrm{a}$ \\
F3 & $53.60 \mathrm{a}$ \\
F1 & $54.60 \mathrm{a}$ \\
\hline BNJ $_{0,05}=2.82$ &
\end{tabular}


Keterangan : Angka-angka yang diikuti oleh huruf yang sama menunjukan bahwa perlakuan berbeda tidak nyata.

\section{Berat Buah per Tanaman Tomat (g)}

Tabel 4 menunjukan pemberian limbah lumpur kering kelapa sawit berpengaruh sangat nyata terhadap berat buah per tanaman. Beda masing-masing perlakuan berdasarkan uji BNJ disajikan pada tabel 4.

Tabel 4. Pengaruh pemberian limbah lumpur kering kelapa sawit terhadap berat buah (g) tanaman tomat.

\begin{tabular}{lllllll}
\hline Perlakuan & $\begin{array}{l}\text { Panen } \\
\text { ke-1 }\end{array}$ & $\begin{array}{l}\text { Panen } \\
\text { ke-2 }\end{array}$ & $\begin{array}{l}\text { Panen } \\
\text { ke-3 }\end{array}$ & $\begin{array}{l}\text { Panen } \\
\text { ke-4 }\end{array}$ & $\begin{array}{l}\text { Panen } \\
\text { ke-5 }\end{array}$ & $\begin{array}{l}\text { Panen } \\
\text { ke-6 }\end{array}$ \\
F1 & 109a & 109a & $99 \mathrm{a}$ & $96 \mathrm{a}$ & $83 \mathrm{a}$ & $83 \mathrm{a}$ \\
F2 & $123 \mathrm{~b}$ & $141 \mathrm{~b}$ & $120 \mathrm{~b}$ & $112 \mathrm{~b}$ & $108 \mathrm{~b}$ & $104 \mathrm{~b}$ \\
F3 & $169 \mathrm{~d}$ & $156 \mathrm{c}$ & $138 \mathrm{c}$ & $128 \mathrm{c}$ & $136 \mathrm{c}$ & $129 \mathrm{c}$ \\
F4 & $151 \mathrm{c}$ & $214 \mathrm{~d}$ & $168 \mathrm{~d}$ & $158 \mathrm{~d}$ & $152 \mathrm{~d}$ & $123 \mathrm{~d}$ \\
F5 & $202 \mathrm{e}$ & $232 \mathrm{e}$ & $197 \mathrm{e}$ & $193 \mathrm{e}$ & $180 \mathrm{e}$ & $150 \mathrm{e}$ \\
\hline BNJ $_{0,05}$ & 0.64 & 0.48 & 0.36 & 0.34 & 0.40 & 0.21 \\
\hline
\end{tabular}

Keterangan : Angka-angka yang diikuti oleh huruf yang sama menunjukan bahwa perlakuan berbeda tidak nyata.

\section{Berat rata-rata per buah (g)}

Hasil analisis keragaman pada tabel 1 menunjukan bahwa pemberian limbah lumpur kering kelapa sawit berpengaruh tidak nyata terhadap rata-rata berat buah. Masing-masing perlakuan uji $\mathrm{BNJ}_{0,05}$ disajikan pada tabel 5 .

Tabel 5. Pengaruh pemberian limbah lumpur kering kelapa sawit terhadap rata-rata berat buah tanaman tomat $(\mathrm{g})$.

\begin{tabular}{ll}
\hline Perlakuan & Rata-rata \\
F1 & $0.109 \mathrm{a}$ \\
F2 & $0.109 \mathrm{a}$ \\
F3 & $0.110 \mathrm{a}$ \\
F4 & $0.113 \mathrm{a}$ \\
F5 & $0.113 \mathrm{a}$ \\
\hline BNJ $_{0,05}=0.01$ & 0.110 \\
\hline
\end{tabular}


Keterangan : Angka-angka yang diikuti oleh huruf yang sama menunjukan bahwa perlakuan berbeda tidak nyata.

Berdasarkan uji BNJ 0,05 tabel 5 tampak bahwa pemberian limbah lumour kering kelapa sawit terhadap rata-rata berat buah berbeda tidak nyata antar semua perlakuan F1,F2,F3,F4,dan F5.

\section{PEMBAHASAN}

Berdasarkan hasil analisis keragaman pada tabel 1 menunjukan bahwa perlakuan pemberian limmbah lumpur kering kelapa sawit berpengaruh nyata terhadap parameter perubah tinggi tanaman tomat pada minggu ke 2 , minggu ke 3 , minggu ke 4 ,dan minggu ke 5, sedangkan pada minggu ke 1 berpengaruh tidak nyata. Penggunaan pupuk organik dapat meningkatakan efisiensi dan untuk menekan pemakaian pupuk anorganik, karena pupuk organil tersebut dapt meningkatkan air dan hara didalam tanah,meningkatkan aktifitas mikroorganisme,mempertinggi kadar humus, dan memperbaiki struktur tanah (Pambudi,2013).

Penambahan lumpur kering kelapa sawit kedalam polybag percobaan nyata meningkatkan pertuimbuhan dan produksi tanaman dibandingkan dengan perlakuan tanpa penambahan limbah lumpur kering kelapa sawit. Menurut sulivan (1998),bahwa limbah lumpur kering kelapa sawit dan bahan organik mengandung banyak nutrisi yang dibutuhkan tanaman.

Pada pengamatan tinggi tanaman tomat pada minggu ke 1 pemberian limbah lumpur kering kelapa sawit berpengaruh tidak nyata. Diduga pupuk organik limbah lumpur kering kelapa sawit belum dapat diserap oleh tanaman tomat karena umut tanaman yang masih muda serta perakaran yang masih sedikit. Sedangkan perlakuan pupuk organic limbah lumour kering kelapa sawit berpengaruh nyata pada pengamatan minggu ke 2,minggu ke 3,minggu ke 4, dan minggu ke 5 diduga umur tanaman tomat yang sudah dewasa dan perakaran yang sudah banyak dapt menyerap unsur hara dari limbah lumpur kering kelapa sawit. Berdasarkan hasil uji $\mathrm{BNJ}_{0,05}$ menunjukan bahwa, perlakuan pupuk limbah lumpur kering memberikan tinggi tanamna yang tertinggi yaitu pada perlakuan F5 minggu ke 5 yaitu dengan rata-rata tinggi $73,42 \mathrm{~cm}$.

Berdasarkan uji $\mathrm{BNJ}_{0,05}$ pemberian limbah lumpur kering kelapa sawit terhadap umur bunga tanaman tomat menunjukan bahwa perlakuan F1 berbeda nyata dengan perlakuan F4 dan F5. Diduga phospat yang ada dalam kandungan limbah lumpur kering kelapa sawit berperan penting untuk merangsang pemb entukan bunga,buah, dan biji selain itu juga untuk merangsang pemasakan buah

Berdasarkan uji $\mathrm{BNJ}_{0,05}$ pengamatan berat buah tomat per tanaman omenunjuka bahwa perlakuan F1 berbeda nyata dengan F2,F3,F4 dan F5 pada panen ke 1,2,3,4,5,dan 6. Diduga bahw akandungan unsur hara yang ada dalam limbah lumpur kering kelapa sawit telah diserap dan mapu memenuhi keutuhan tanaman untuk berbuah. Menurut Lingga (1999), struktur tanah yang dikehendaki tanaman adalah struktur yang gembur yang didalamnya terdapat ruang pori-pori yang dpat diisi pleh air,tanah,dan udara yang amat pentng bagi pertumbuhan akar tanaman. Keuntunganya ialah udara dan air tanah berjalan lancar, temperaturnya stabil,,artinya sangat memacu pertumbuhan jasad renik tanah yang memegang peranan penting dalam prose pelapukan bahan organik didalam tanah.

Berdasarkan uji $\mathrm{BNJ}_{0,05}$ pada pengamatan jumlah buah tomat per tanaman, pemberian limbah lumpur kering kelapa sawit pada panen ke 1, perlakuan F1, F2,F3, dan F4 berbeda nyata dengan perlakuan F5. 
Diduga karena unsur hara terbanyak pada perlakuan F5 memberikan peranan penting pada parameter jumlah buah. Sedangkan pada panen ke 2,3,4,5,dan 6 perlakuan $\mathrm{F} 1$ menunjukan rata-rata terkecil dibanding F2,F3,F4, dan F5. Diduga karena pada perlakuan F1 tidak ada pemberian limbah lumpur kering kelapa sawit sehingga unsur yang terkandung dalam tanah kurang maksimal untuk memenuhi kebutuhan tanaman tomat.

\section{KESIMPULAN}

Berdasarkan hasil penelitian yang telah dilakukan dapat disimpulkan bahwa pemberian limbah lumpur kering kelapa sawit berpengaruh baik terhadap tinggi tanaman tomat, umur tomat berbunga,jumlah buah tomat, dan berat buah tomat. Artinya limbah lumpur kering kelapa sawit berpengaruh baik terhadap pertumbuhan dan produksi tanaman tomat (Solanum lycopersicum L)

\section{DAFTAR PUSTAKA}

Abdoellah, P. 2002. Pemanfaatan Limbah Kelapa Sawit. Bogor. Diakses dari www.wikipedia.com,pada tanggal 4 Juni 2014.

Bergeret, A. 1987. Sistem Produksi Menurut Pendekatan Ekologis dalam Ekofarming Bertani Selaras Alam. Yayasan Obor Indonesia. Jakarta

Elisabeth, J dan S. Ginting. 2003. Pemanfaatan Hasil Samping Industri Kelapa

Sawit sebagai Bahan Pakan

Ternak Sapi Potong. Badan Penelitian Dan

Pengembangan Pertanian Bengkulu. Bengkulu.
Falma. 2011. Pemanfaatan Limbah Lumpur Kering Kelapa Sawit terhadap Perbaikan Sifat Kimia Tanah serta Pengaruhnya terhadap Serapan Hara dan Hasil Tenaman Jagung (Zea mays saccharata sturt) pada Ultisol. Diakses dari http://repository.unand.ac.id/20042/, pada tanggal 21 Oktober 2014.

Hutagalung, R dan Jalaluddin. 2006. Feedd for Farm Animal from The Oil Palm. Departemen. of Animal Science University. Serdang.

Ismawati, E. 2003. Pupuk Organik. Penebar Swadaya. Bogor

Lingga. 1999. Petunjuk Penggunaan Pupuk. Penebar Swadaya. Jakarta.

Mulyani, M. 2010. Pupuk dan Cara Pemupukan. Rineka Cipta. Jakarta.

Munandar, 2001. Tanaman Tomat. Sinar Baru Algensindo. Bandung.

Pambudi, S. 2013. Budidaya dan Khasiat Kedelai Edamame. Pustaka Baru Press.Yogyakarta.

Pitidjo, S. 2005. Benih Tomat. Kanisius. Yogyakarta.

Pracaya. 2004. Bertanam Tomat. Kanisius. Yogyakarta.

Siregar dan Supriati. 2009. Bertanam Tomat dalam Pot dan Polybag. Penebar Swadaya. Bogor.

Sullivan, D. 1998. Fertilizing with Biosolids. Pacific Northwest Extension Publication. Oregan State University Extension Service, Corvalis Washington.

Utomo, B dan Widjaja, E. 2004. Limbah Padat Pengolahan Minyak Sawit sebagai Sumber Nutrisi Ternak Ruminansia. Balai Teknologi Pertanian Kalimantan Tengah. Palangkaraya. Diakses dari www.pustakadeptan.go.id/publikasi/p3231044.pdf, pada tanggal 4 Juni 2014 
